\title{
Infecção por micobactéria após videoartroscopia: o glutaraldeído pode ser o culpado? Estudo experimental in vitro*
}

\author{
Mycobacterial Infection after videoarthroscopy: \\ could glutaraldehyde be the culprit?
}

An in vitro experimental study

\author{
lúcio honório de Carvalho Júnior ${ }^{1}$, Marcelo lobo Pereira², lincoln Paiva Costa², \\ Matheus Braga Jacoues Gonçalves ${ }^{3}$, Luiz Fernando Machado Soares ${ }^{3}$, \\ Rogério luciano Santos ${ }^{4}$, Ronaldo Percopi de ANdRade ${ }^{5}$, Eurí́tedes de Alvarenga Barbosa ${ }^{6}$
}

\section{RESUMO}

Objetivo: Os autores avaliaram in vitro o poder de degermação do glutaraldeído a $2,2 \%$ por 30 minutos, nas lâminas de shaver de $3,2 \mathrm{~mm}$ de diâmetro, usadas em videoartroscopias. Métodos: Foram utilizadas 40 lâminas, de $3,2 \mathrm{~mm}$, subdivididas em

* Trabalho realizado no Hospital Madre Teresa de Belo Horizonte (MG), Brasil.

1. Doutor, Professor do Departamento do Aparelho Locomotor da Faculdade de Medicina da UFMG, Membro do Grupo do Joelho do Hospital Madre Teresa de Belo Horizonte - Belo Horizonte (MG), Brasil.

2. Residente do Hospital Madre Teresa - Belo Horizonte (MG), Brasil.

3. Membro do Grupo do Joelho do Hospital Madre Teresa - Belo Horizonte (MG), Brasil.

4. Médico estagiário do Grupo do Joelho do Hospital Madre Teresa - Belo Horizonte (MG), Brasil.

5. Chefe do Grupo de Cirurgia do Ombro e Cotovelo e do Serviço de Ortopedia do Hospital Madre Teresa - Belo Horizonte (MG), Brasil.

6. Médico Patologista Clínico do Hospital Madre Teresa - Belo Horizonte (MG), Brasil.

Endereço para correspondência: Rua Olavo Carsalade Vilela, 264, Residencial Ipê da Serra, Nova Lima - 34000-000 - Minas Gerais (MG), Brasil. E-mail: luciohcj@medicina.ufmg.br

Recebido em 12/2/08. Aprovado para publicação em 19/6/08.

Copyright RBO2008 quatro grupos. Grupo I: 10 lâminas esterilizadas em óxido de etileno foram colocadas de forma estéril no meio de cultura Brain-heart infusion (BHI). Grupo II: 10 lâminas esterilizadas em óxido de etileno foram deliberadamente contaminadas pelas bactérias Staphylococcus aureus, Pseudomonas aeruginosa, Escherichia coli, Streptococcus faecalis e Mycobacterium fortuitum e posteriormente colocadas no meio de cultura BHI. Grupo III: 10 lâminas esterilizadas em óxido de etileno foram contaminadas pelas mesmas bactérias e posteriormente imersas por 30 minutos em glutaraldeído e, após limpeza com soro fisiológico, colocadas no meio de cultura. Grupo IV: 10 lâminas esterilizadas em óxido de etileno foram utilizadas em artroscopias, posteriormente lavadas e imersas em glutaraldeído, também colocadas em meio de cultura. Nos meios onde houve crescimento bacteriano, este foi verificado em 72 horas de incubação, sendo esse tempo prolongado para sete dias para recuperação da micobactéria. Resultados: Não houve crescimento de germes nos meios de cultura dos grupos I, III e IV, mas houve crescimento em todas as amostras do grupo II. Conclusão: A solução de glutaraldeído a $2,2 \%$, dentro do prazo de validade, utilizada por 30 minutos, mostrou-se eficaz, in vitro, na degermação de lâminas de shaver de $3,2 \mathrm{~mm}$ de diâme- 


\section{tro, mesmo quando deliberadamente contaminadas por micobactéria de crescimento rápido.}

Descritores - Esterilização/métodos; Glutaral/análise; Artroscopia/métodos; Estudos experimentais

\section{ABSTRACT}

Objective: The authors made an in vitro assessment of the degermation power of $2.2 \%$ glutaraldehyde for 30 minutes in $3.2 \mathrm{~mm}$ diameter shaver blades used in videoarthroscopy. Methods: $403.2 \mathrm{~mm}$ blades were used after being subdivided into four groups: Group I - 10 blades sterilized with ethylene oxide were placed in sterile state in a Brain-heart infusion (BHI) culture medium; Group II - ten blades sterilized with ethylene oxide were deliberately contaminated with Staphylococcus aureus, Pseudomonas aeruginosa, Escherichia coli, Streptococcus faecalis, and Mycobacterium fortuitum and later placed in a BHI culture medium; Group III - 10 blades sterilized with ethylene oxide were contaminated by the same bacteria and later immersed in glutaraldehyde for 30 minutes, and after they were cleaned with saline solution, they were placed in the culture medium; Group IV - 10 blades sterilized with ethylene oxide were used in arthroscopic procedures, then washed an immersed in glutaraldehyde, and also placed in the culture medium. In the media were bacterial growth did occur, such growth was seen within 72 hours of incubation, such period being extended to seven days to retrieve mycobacteria. Results: There was no germ growth in the culture media of Groups I, III, and IV, but bacteria grew in all samples of Group II. Conclusion: The 2.2\% glutaraldehyde solution, within the validity period, used for 30 minutes, showed to be effective "in vitro", in the degermation of $3.2 \mathrm{~mm}$ Shaver blades even when they were deliberately contaminated by fast-growing mycobacteria.

Keywords - Sterilization/methods; Glutaral/analysis; Arthroscopy/methods

\section{INTRODUÇÃO}

A videoartroscopia é procedimento corriqueiro nos mais diversos hospitais, possibilitando rápida recupe- ração pela mínima agressão cirúrgica ao paciente. Durante sua realização utilizam-se diversos dispositivos de pequeno diâmetro, entre eles um "barbeador" (shaver) acoplado a sistema de aspiração que permite raspagem e sucção simultâneos. A lâmina desse último geralmente é descartável e de uso único, podendo, contudo, ser reaproveitada, em caso de necessidade, para um segundo ou terceiro procedimento ${ }^{(1)}$.

Seu reaproveitamento envolve nova esterilização, geralmente realizada com óxido de etileno ou, eventualmente, autoclavagem. É possível ainda sua degermação utilizando imersão em glutaraldeído. O tempo de imersão pode variar dependendo do objetivo, contudo, nunca é inferior a 30 minutos $^{(1)}$.

Relatos recentes têm divulgado o aparecimento de abscessos tardios em videolaparoscopias e mamoplastias com implantes que utilizam processos semelhantes de degermação. O germe envolvido nesses relatos é um grupo de micobactéria de crescimento rápido (MCR $-m$. abcessus $/ m$. fortuitum $/ m$. chelonae $)^{(2-4)}$.

A legislação brasileira permitia, até dezembro de 2007, que materiais descartáveis tubulares com diâmetro maior do que 3,0 $\mathrm{mm}$ fossem submetidos a processo de degermação de alto nível por imersão em glutaraldeído ${ }^{(5)}$.

A Secretaria de Estado da Saúde de Minas Gerais publicou Portaria em 16/7/2007, segundo a qual, em seu Inciso II do artigo 3 da Resolução no 860, de 22/ 3/2006, todos os estabelecimentos de Saúde do Estado deveriam suspender a esterilização por meios químicos para artigos críticos, entre eles, as lâminas de shaver utilizadas nas videoartroscopias. A mesma Secretaria estabeleceu prazo de 180 dias, a partir da data da publicação, para que tais medidas fossem implementadas $^{(5)}$.

O objetivo deste estudo é avaliar, in vitro, o poder de degermação do glutaraldeído a 2,2\% por 30 minutos, nas lâminas descartáveis utilizadas em videoartroscopias.

\section{MÉTODOS}

Foram utilizadas 40 lâminas idênticas, de 3,2 milímetros de diâmetro, de videoartroscopia, subdividi- 
das em quatro grupos: Grupo 1: após esterilização em óxido de etileno, 10 lâminas foram colocadas de forma estéril no meio de cultura Brain-heart infusion (BHI), em tubo de ensaio especial que permitia a submersão de toda a lâmina de shaver. Grupo 2: após esterilização em óxido de etileno, 10 lâminas foram deliberadamente contaminadas por imersão durante 30 segundos em tubo de ensaio contendo suspensão bacteriana individual de Staphylococcus aureus, Pseudomonas aeruginosa, Escherichia coli, Streptococcus faecalis e Mycobacterium fortuitum (duas lâminas para cada tipo) e posteriormente colocadas no meio de cultura BHI. Grupo 3: após esterilização em óxido de etileno, 10 lâminas foram, da mesma forma que no grupo anterior, contaminadas por imersão durante 30 segundos, pelas mesmas bactérias supracitadas (duas lâminas para cada tipo), imersas por 30 minutos em solução de glutaraldeído a 2,2\%, lavadas com soro fisiológico (SF) a $0,9 \%$ por dois minutos e colocadas no meio de cultura BHI. Grupo 4: após esterilização em óxido de etileno, 10 lâminas foram utilizadas em 10 videoartroscopias em 10 diferentes pacientes, lavadas com soro fisiológico (SF) a $0,9 \%$, por dois minutos, imersas por 30 minutos em glutaraldeído a 2,2\% e novamente lavadas com soro fisiológico (SF) a $0,9 \%$ por dois minutos, sendo então colocadas no meio de cultura BHI.

A manipulação das lâminas foi feita em câmara de fluxo laminar, utilizando equipamentos de proteção individual, inclusive máscara específica para micobactérias e óculos.

Após incubação por 14 horas, as lâminas foram retiradas dos tubos e a solução de BHI distribuída em outros tubos de ensaio medindo 18 x 180mm. Centrifugados a 3.500 rotações por minuto durante cinco minutos, produziram "sedimento", que foi semeado em meios específicos que contemplavam as exigências de crescimento de cada uma das bactérias e respectivas provas bioquímicas de validação: Staphylococcus aureus (ágar sangue, manitol e chocolate, catalase, coagulase e Dnase), Pseudomonas aeruginosa (ágar-McConkey, Pessoa e Silva, produção de piocianina e oxidase), Escherichia coli (ágar sangue, ágar-McConkey, Pessoa e Silva), Streptococcus faecalis (ágar sangue,
CAMP-teste, BHI a 6,5\%, bile-esculina) e Mycobacterium fortuitum (ágar sangue e Loweinstein-Jeensen).

As colorações realizadas nas diferentes etapas do processo (caracterização da pureza do inóculo, isolamento da colônia recuperada após incubação e conferência da concentração da suspensão bacteriana) foram feitas pelo gram e observadas ao microscópio ótico convencional.

Nos meios onde houve crescimento bacteriano, este foi verificado em 72 horas de incubação, sendo esse tempo prolongado para sete dias para recuperação da micobactéria.

Foi obtido consentimento pós-informado por escrito dos 10 pacientes do grupo 4 . O projeto de pesquisa foi apresentado e aprovado pela Comissão de Ética em Pesquisa do Hospital Madre Teresa de Belo Horizonte.

\section{RESULTADOS}

Após análise das culturas, incubadas por sete dias, não se observou crescimento em nenhuma das amostras do grupo 1.

Após incubação e nova semeadura nos meios específicos já citados, houve crescimento de germes em todas as amostras do grupo 2 . Os germes recuperados foram avaliados e confirmou-se serem aqueles originalmente semeados.

Conforme detalhado em "Métodos", após permanecerem por 30 minutos em solução de glutaraldeído a $2,2 \%$, semeados no meio BHI, centrifugados e novamente semeados em meio de cultura específico e analisados por até sete dias após a semeadura, não houve crescimento de germes nos meios de cultura do grupo 3 e do grupo 4.

\section{DISCUSSÃO}

Desinfecção ou degermação é o método de eliminação de microorganismos patogênicos, com exceção de esporos. Quando de alto nível (como a obtida por glutaraldeído, água oxigenada, hipoclorito de sódio, ácido acético ou pasteurização), bactérias esporuladas e vírus lentos resistem ao procedimento. Desinfecção ou degermação de nível médio destrói bactérias em forma vegetativa, alguns vírus (como o de herpes) e a maioria dos fungos. Na desinfecção de baixo nível são 
destruídas bactérias em forma vegetativa, alguns vírus e alguns fungos ${ }^{(6)}$.

$\mathrm{Na}$ escala decrescente de resistência aos métodos de esterilização/degermação atualmente utilizados, podemos citar: 1) príons (como os causadores da doença de Creutzefeld-Jacob); 2) bactérias esporuladas ( $\mathrm{Ba}$ cillus sp., Clostridium sp.); 3) micobactérias (tuberculose e aquelas de crescimento rápido); 4) vírus não lipídicos (poliovírus, rinovírus); 5) fungos (Candida $s p$.); 6) bactérias vegetativas (Enterococcus sp., Pseudomonas sp., Staphylococcus sp.); e 7) vírus lipídicos $(\mathrm{HBV}, \mathrm{HIV})^{(6)}$.

O M. fortuitum é um microorganismo ubíquo, capaz de produzir doença em humanos sob condições apropriadas. As infecções associadas a ele incluem doença pulmonar, endocardite, otite média, mastoidite e ceratite. Outros tipos de infecções causadas por Mycobacterium (abcessus/fortuitum/chelonae) foram identificados em procedimentos cirúrgicos estéticos como liposucção e lipoescultura, administração parenteral de vitaminas, extrato de córtex adrenal, lidocaína, silicone, tratamento de acupuntura, colocação de piercing mamilar e banhos em piscinas, uma vez que essa bactéria já foi encontrada em água tratada nas caixas d'água de hospitais ${ }^{(7-14)}$. Sua presença nesses locais implica desdobramentos preocupantes, uma vez que foi fonte de problemas em vários setores de serviços de saúde, sendo associadas com fluidos de hemodiálise e soluções desinfetantes ${ }^{(6-7,13)}$. No Brasil são poucos os casos publicados de infecções por MCR, sendo encontrados casos após correções de miopia e após cirurgias plásticas. Podem envolver praticamente qualquer tecido, órgão ou sistema do corpo humano, sendo mais freqüiente o acometimento da pele e do subcutâneo. Não existem relatos de transmissão pessoa a pessoa, sendo as fontes ambientais as mais importantes ${ }^{(15)}$.

A capacidade de esterilização ou de degermação de alto nível de qualquer solução desinfetante depende da sua capacidade de penetrar adequadamente na superfície a ser tratada e da prévia retirada por limpeza mecânica de remanescentes teciduais que possam manter o patógeno dentro do objeto. Esses são os pré-requisitos a serem observados quando da reesterilização de cânulas ou lâminas de videoartroscopia. Todas aque- las providas de sistema de válvulas ou ainda extremamente finas que não permitam adequada limpeza de sua luz não são passíveis de esterilização ou degermação de alto nível pela utilização do glutaraldeído ${ }^{(16)}$. A lâmina de shaver de 3,2 milímetros não se enquadra em nenhuma dessas limitações.

Comunicados da Agência Nacional de Vigilância Sanitária alertam que 30 minutos de imersão no glutaraldeído não seriam suficientes para a eliminação de esporos bacterianos. Tal preocupação é irrelevante em relação às bactérias testadas, visto que nenhuma delas forma esporos, inclusive o grupo das micobactérias ${ }^{(17)}$.

A qualidade das lâminas de shaver quando reutilizadas possivelmente fica comprometida, visto que originalmente foram confeccionadas como material de uso único. Atentos a isso e à possibilidade de transmissão de doenças, Johnson et al analisaram 12.505 artroscopias reutilizando materiais após 15 minutos de imersão em solução de glutaraldeído a 2,0\%. Encontraram infecção pós-operatória em $0,04 \%$ dos casos; em $80 \%$ destes, após a artroscopia se realizou procedimento por artrotomia. Esse percentual é menor do que o esperado para qualquer cirurgia limpa ${ }^{(18)}$. King et al, usando óxido de etileno como recurso de esterilização, encontraram níveis elevados de proteínas "estranhas" em $48 \%$ das lâminas reutilizadas e $63 \%$ delas com ácidos nucléicos também "estranhos"(19).

Retta et al, testando a forma esporulada do bacillus athrophaeus, desenvolveram modelo matemático para avaliar como o glutaraldeído poderia ser eficaz para destruir tais esporos. Para tal, o tempo de uso, a concentração e a temperatura do gluraraldeído teriam de ser aumentados ${ }^{(20)}$.

Apesar da efetividade sobre várias bactérias (esporuladas ou não), algumas são capazes de desenvolver resistência ao glutaraldeído. Atentos a esse risco, Walsh et al sugerem que, face a essa eventualidade, mudanças no $\mathrm{pH}$ ou na concentração poderiam ser suficientes para eliminar tal resistência. Outra opção seria o uso de outro aldeído (orto-ftalaldeído), sabidamente efetivo nessa eventualidade, inclusive contra bactérias esporuladas $^{(21)}$.

Como todo estudo in vitro, os achados deste trabalho não podem ser imediatamente aplicadas à situa- 
ção in vivo, onde diversos são os fatores que podem interferir na resposta agressor-hospedeiro.

\section{CONCLUSÃO}

A solução de glutaraldeído a 2,2\%, dentro do prazo de validade, utilizada por 30 minutos, mostrou-se eficaz, in vitro, na desinfecção de lâminas de shaver de 3,2 milímetros de diâmetro, mesmo quando deliberadamente contaminadas por micobactéria de crescimento rápido.

\section{Nota do Editor \\ A Resolução no 2.606, da Anvisa, datada de 11-6- 08, proíbe o uso do glutaraldeído como meio de de- germação de materiais cirúrgicos. Este trabalho deve ser considerado como experimental e a sua conclusão não implica respaldo da $R B O$ à sua apli- cação prática.}

\section{REFERÊNCIAS}

1. Telini AC, Fernandes RR, Kerr C. Estudo da eficácia do glutaraldeído a 2,4 por cento na desinfecção do material artroscópico. Rev Bras Ortop. 1993;28(8):541-4.

2. São Paulo. Secretaria de Estado da Saúde de São Paulo. Centro de Vigilância Epidemiológica "Prof. Alexandre Vranjac". Comunicado sobre infecções por Mycobacterium fortuitum pós implante mamário na cidade de Campinas. [Internet].[citado 2005 Ago 15]. Disponível em: www.cve.saude.sp.gov.br

3. Ryu HJ, Kim WJ, Oh CH, Song HJ. Iatrogenic mycobacterium abscessus infection associate with acupuncture: clinical manifestations and its treatment. Int J Dermatol. 2005;44(10): 846-50.

4. Newman MI, Camberos AE, Ascherman J. Mycobacteria abscessus outbreak in US patients linked to Offshore Surgicenter. Ann Plast Surg. 2005;55(1):107-10; discussion 110.

5. Secretaria de Estado de Saúde de Minas Gerais. Subsecretaria de Vigilância em Saúde. Superintendência de Vigilância Sanitária. Gerencia de Vigilância em Estabelecimentos de Saúde. Notificação da Gerência Colegiada da Superintendência de Vigilância Sanitária № 203/2007/GVES. [Internet]. [citado 2008 Jan 15]. Disponível em: http://www.saude.mg.gov.br/publicacoes/ estatistica-e-informacao-em-saude/alertas-tecnicos/notificacao 203.pdf

6. Brown BA, Wallace RJ Jr. Infections caused by nontuberculous mycobacteria In: Mandell GL, Bennett JE, Dolin R, editors. Principle and practice of infectious diseases. $6^{\text {th }}$ ed. New York: Elsevier/Churchil Livingstone; c2005. p. 2909-16.
7. Centers for Disease Control and Prevention. Mycobateryum abscessus frequently asked questions. [Internet].[cited 2005 Ago 15]. Available from: www.cdc.gov/incidod/hip/myco/ivi abscessus faq prt.htm

8. Centers for Disease Control and Prevention (CDC). Rapidly growing mycobacterial infection following liposuction and liposculputure - Caracas, Venezuela, 1996-1998. MMWR Morb Mortal Wkly Rep. 1998;47(49):1065-7.

9. Clegg HW, Bertagnoll P, Hightower AW, Baine WB. Mammaplasty-associated mycobacterial infection: a survey of plastic surgeons. Plast Reconstr Surg. 1983;72(2):165-9.

10. Galil K, Miller LA, Yakrus MA, Wallace RJ Jr, Mosley DG, England B, et al. Abscesses due to mycobacterium abscessus linked to injection of unapproved alternative medication. Emerg Infect Dis. 1999;5(5):681-7.

11. Clegg HW, Foster MT, Sanders WE Jr, Baine WB. Infection due to organisms of mycobacterium fortuitum complex after augmentation mammaplasty: clinical and epidemiologic features. J Infect Dis. 1983;147(3):427-33.

12. Haiavy J, Tobin H. Mycobacterium fortuitum infection in prosthetic breast implants. Plast Reconstr Surg. 2002;109(6): 2124-8.

13. Wagner D, Young LS. Nontuberculous mycobacterial infections: a clinical review. Infection. 2004;32(5):257-70.

14. Winthrop RL, Albridge K, South D, Albrecht P, Abrams M, Samuel MC, et al. The clinical management and outcome of nail salon-acquired mycobacterium fortuitum skin infection. Clin Infect Dis. 2004;38(1):38-44.

15. Höfling-Lima AL, de Freitas D, Sampaio JL, Leão SC, Contarini P. In vitro activity of fluoroquinolones against mycobacterium abscessus and mycobacterium chelonae causing infectious keratitis after LASIK in Brazil. Cornea. 2005;24(6):730-4.

16. Brasil. Ministério da Saúde. Agência Nacional de Vigilância Sanitária. Resolução no 2605 de 11 de Agosto de 2006 [Internet]. Brasília (DF): Ministério da Saúde; c2005. [citado 2008 Jun 21] Disponível em http://www.saude.mg.gov.br/atos_ normativos/legislacao-sanitaria/estabelecimentos-de-saude/produtos-para-a-saude/res_2605.pdf

17. Agência Nacional de Vigilância Sanitária (ANVISA). Informe técnico no 04/07 [Internet]. Brasília (DF):ANVISA; [citado 2008 Jan 15]. Disponível em: http://www.anvisa.gov.br/ serviçossaude/controle/alertas/informetecnico04.pdf

18. Johnson LL, Shneider DA, Austin MD, Goodman FG, Bullock JM, DeBruin JA. Two per cent glutaraldehyde: a disinfectant in arthroscopy and arthroscopic surgery. J Bone Joint Surg Am. 1982;64(2):237-9.

19. King JS, Pink MM, Jobe CM. Assessment of reprocessed arthroscopic shaver blades. Arthroscopy. 2006;22(10):104652.

20. Retta SM, Sagripanti JL. Modeling the inactivation kinetics of bacillus spores by glutaraldehyde. Lett Appl Microbiol. 2008; 46(5):568-74.

21. Walsh SE, Maillard JY, Russell AD. Ortho-phthalaldehyde: a possible alternative to glutaraldehyde for high level disinfection. J Appl Microbiol. 1999;86(6):1039-46. 